\title{
Diverse Sources of Stem Cells to Treat Acute Kidney Injury
}

\author{
Asif Zakaria Yanfei Huang Karl Womer Hamid Rabb \\ Nephrology Division, Johns Hopkins University, Baltimore, Md., USA
}

Ischemic acute kidney injury (AKI) decreases allograft survival in kidney transplants and increases mortality when occurring in native kidneys [1]. There is currently no specific treatment, thus there is an important need to develop novel ways to decrease early injury and augment repair. There is great promise in the application of stem cells for AKI, and the mechanisms by which stem cells work are largely unknown $[2,3]$. Putative mechanisms of stem cell action have included transdifferentiation, fusion of stem cells into damaged tissue, immunomodulation, production of paracrine growth factors, or a combination of these mechanisms. Furthermore, it was once believed that stem cells originating from a particular tissue would support and construct tissue of similar type only. Recent studies challenge the notion of linear and unidirectional differentiation of lineage-committed adult stem cells. New lines of evidence invoke transdifferentiation to a wider spectrum of differentiated progeny than previously claimed $[4,5]$. Undifferentiated or already differentiated cells or tissue-specific stem cells have been shown to alter their phenotype to express functional characteristics of a different tissue. These types of conversions are referred to as transdifferentiation or metaplasia and are accompanied by change in tissue-specific cell surface markers and phenotype. Another novel approach is to harness paracrine factors produced by stem cells and apply them to injured tissue to simulate stem cell repair function.

In the current issue of Nephron, Wang et al. [pp e20e28] from Brazil have elegantly demonstrated that neural precursor cells (NPCs) can be protective in a rat ischemic AKI model. Fetal rat telencephalon-derived neurospheres were administered intravenously (i.v.), intraperitoneally (i.p.), and intracortically $4 \mathrm{~h}$ following $1 \mathrm{~h}$ of kidney ischemia. Control cells were homogenates from adult rat cerebellum. Intravenous administration of the neural precursor cells was highly effective in reducing the kidney dysfunction and structural damage at $24 \mathrm{~h}$, and some benefit was seen from i.p. and intracortical administration as well. Labeled NPCs tracked to injured kidney, and there were enhanced levels of anti-inflammatory cytokines IL-4 and IL-10, while reduced levels of proinflammatory cytokines IL-1 and TNF in the kidney. Furthermore, macrophage infiltration was reduced after NPC administration. The authors are likely the first to demonstrate that NPCs are effective in AKI, which is an important conceptual advance in the field of stem cells and kidney diseases. A strength is that the design is clinically geared, studying various forms of administration. The injured kidney is providing homing signals that attract these progenitor cells, though what these are is unknown. The reduced macrophage trafficking and alterations in soluble inflammatory molecules are suggestive of an immune/anti-inflammatory mechanism of action, however reduced injury through other mechanisms may have led to this inflammatory profile. These fascinating results raise many questions. What are these NPCs making and could glial-derived neurotropic factor (GDNF) be one of these protective factors, as already demonstrated with GDNF administration $[6,7]$ ? Can other areas of the brain

\section{KARGER}

Fax +41 613061234 E-Mail karger@karger.ch www.karger.com
(C) 2009 S. Karger AG, Basel

$1660-2129 / 09 / 1121-0029 \$ 26.00 / 0$

Accessible online at:

www.karger.com/nee
Hamid Rabb

Ross 965, 720 Rutland Ave

Johns Hopkins University

Baltimore, MD 21205 (USA)

Tel. +1 410502 1555, Fax +1 410614 5129, E-Mail hrabbl@jhmi.edu 


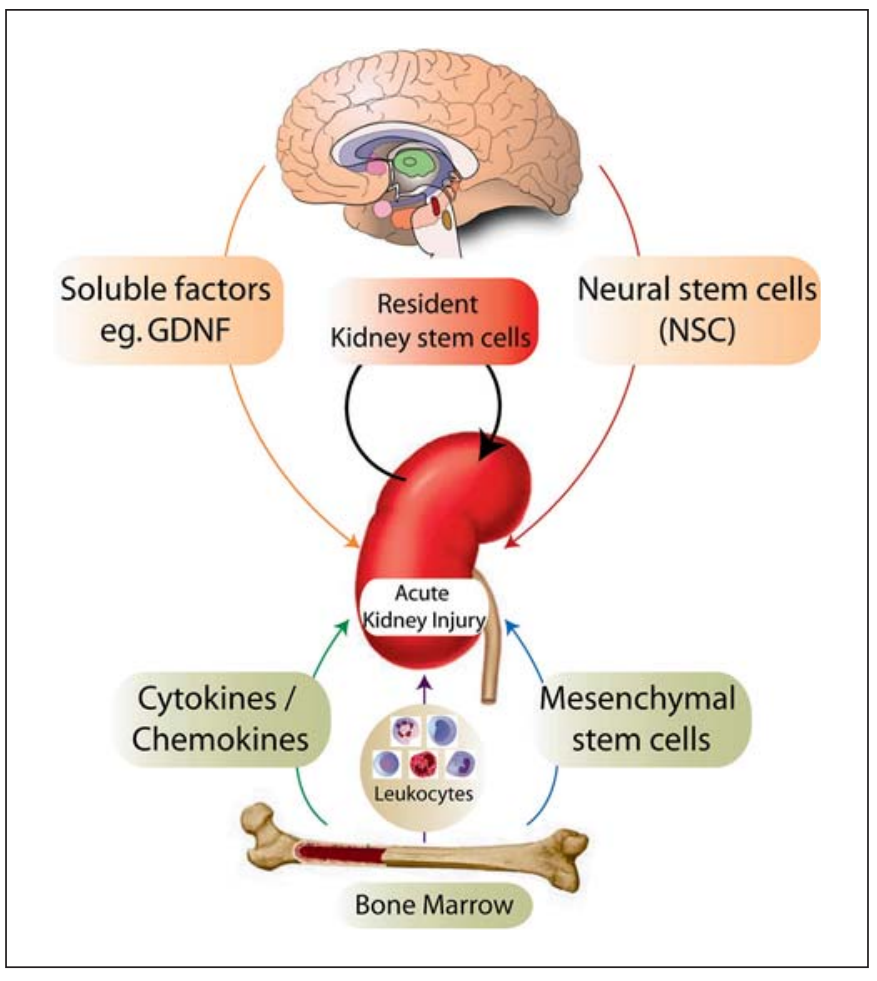

Fig. 1. Stem cells, leukocytes and soluble factors in repair from acute kidney injury. Stem cells from diverse sources including kidney, brain and bone marrow can participate in repair from acute kidney injury in conjunction with soluble factors. make these NPCs, and can adult brain be a source of these kidney protective NPCs? The control cells came from adult cerebellum, but perhaps a non-cerebellar source of stem cells from adult rat brain would have been protective. The cross-talk between AKI and brain has already been demonstrated and could be an important regulator of both injury and repair of both organs [8]. Isolation of NPCs and study in culture could reveal the mechanisms. Recently, study of adult murine kidney progenitor cells in vitro has demonstrated a marked immunologic effect on maturation of dendritic cells and T-cell proliferation, as well as identification of soluble mediators that carry out these effects. It is conceivable that the administered NPCs were stimulating the endogenous kidney progenitor cells to generate anti-inflammatory effects during AKI [9]. One of the important messages emanating from the current NPC article by Wang et al. is that it is important to study various sources of stem cells for AKI and other renal diseases. These other sources include bone marrow-derived, resident kidney, and stem cells originating from distant organs like brain (fig. 1). Each of these different sources could have particular strengths and unique effects on the injured kidney. Clearly, the field of stem cells is changing rapidly and previous dogma about the utility of only embryonic or bone marrow-derived mesenchymal cells is no longer valid.

\section{References}

1 Clarkson MR, Friedwald JJ, Eustace JA, Rabb $\mathrm{H}$ : Acute kidney injury; in Brenner BM (ed): Brenner and Rector's The Kidney. Philadelphia, Saunders Elsevier, 2008, vol 1, pp 943986.

-2 Duffield JS, Park KM, Hsiao LL, Kelley VR, Scadden DT, Ichimura T, Bonventre JV: Restoration of tubular epithelial cells during repair of the postischemic kidney occurs independently of bone marrow-derived stem cells. J Clin Invest 2005;115:1743-1755.

- 3 Togel F, Hu Z, Weiss K, Isaac J, Lange C, Westenfelder C: Administered mesenchymal stem cells protect against ischemic acute renal failure through differentiation-independent mechanisms. Am J Physiol Renal Physiol 2005;289:F31-F42.
4 Ross JJ, Verfaillie CM: Evaluation of neural plasticity in adult stem cells. Philos Trans R Soc Lond B Biol Sci 2008;363:199-205.

5 Wagers AJ, Weissman IL: Plasticity of adult stem cells. Cell 2004;116:639-648.

-6 Shi H, Patschan D, Dietz GP, Bahr M, Plotkin M, Goligorsky MS: Glial cell line-derived neurotrophic growth factor increases motility and survival of cultured mesenchymal stem cells and ameliorates acute kidney injury. Am J Physiol Renal Physiol 2008;294: F229-F235.
Orth SR, Ritz E, Suter-Crazzolara C: Glial cell line-derived neurotrophic factor (GDNF) is expressed in the human kidney and is a growth factor for human mesangial cells. Nephrol Dial Transplant 2000;15:589595.

8 Liu M, Liang Y, Chigurupati S, Lathia JD, Pletnikov M, Sun Z, Crow M, Ross CA, Mattson MP, Rabb H: Acute kidney injury leads to inflammation and functional changes in the brain. J Am Soc Nephrol 2008; 19:13601370.

9 Huang Y, Johnston P, Zhang B, Zakaria A, Chowdhry T, Smith RR, Marbán E, Rabb H, Womer KL: Kidney-derived stromal cells modulate dendritic and $\mathrm{T}$ cell responses. $\mathrm{J}$ Am Soc Nephrol, in press. 